\title{
Information Seeking Behavior of Older Adults in a Public Library in Japan
}

\author{
Norihiko Uda, Chieko Mizoue, and Saori Donkai \\ Faculty of Library, Information and Media Science, \\ University of Tsukuba, Japan \\ uda@slis.tsukuba.ac.jp;mizoue@slis.tsukuba.ac.jp;donkai@slis.tsukuba.ac.jp
}

\author{
Saki Ishimura \\ Tottori City Office, Japan \\ ishimura.saki.mg@alumni.tsukuba.ac.jp
}

\begin{abstract}
Background. Services for older adults are becoming accepted as a separate user service category at Japanese public libraries. From the perspective that older adults are themselves supposed to support the community in this super-aged society, there is a growing need to give positive assistance to older adults as library patrons and information seekers.

Objectives. This paper examines the information seeking behavior of older adults at a public library, including how they select information search tools, as well as their reasons and perception underlying such behavior.

Methods. Experiments were conducted at a public library to investigate actual information behavior, and interviews were carried out to clarify user perceptions of public libraries and user needs.

Results. The information seeking behavior of older adults at public libraries can be categorized into three patterns: Case 1 where the Library Usage Frequency is High; Case 2 where the Library Usage Frequency is Low and There is Preference for Search Method; and Case 3 where the Library Usage Frequency is Low and There is No Preference for Search Method.

Contributions. The study has identified some information seeking behavior patterns of older adults at public libraries. Some challenges in current services are identified, and directions for future services to older adults are proposed.
\end{abstract}

\section{INTRODUCTION}

Older adults of 65 years and older comprised $27.3 \%$ of the total population (127 million) of Japan, as of September 15, 2016. This ratio is the highest among the countries of the world (Statistics Bureau, Japan, 2016). Around a quarter of the older adults have difficulty with their daily lives due to health problems (Cabinet Office, 2016). Meanwhile, it is reported that $61.0 \%$ of older adults aged 60 and above participated in some kind of lifelong learning activity (Cabinet Office, 2016).

Under such circumstances, services for older adults at Japanese public libraries, previously subsumed under services for disabled people, are becoming accepted as a separate library patron category. From the perspective that older adults are expected to maintain their 
own community by themselves in this super-aged society (Cabinet Office, 2018), there is a growing need to give positive assistance to older adults as library patrons, readers and information seekers. Not all older adults are unfamiliar with information communication technology and a layer of older adults who spend time proactively engaging in leisure activities and seeking information has been expanding (Hayashi, 2015). Also, the usage of Internet by older adults in Japan has been increasing year by year (Ministry of Internal Affairs and Communications, 2012).

In the context of the changing environment that older adults cope with, it is timely to find out what information seeking behavior they adopt at public libraries. This research examined the information seeking behavior of older adults who are able to visit public libraries and implement their own searching. More specifically, the study sought to find out how they select information search tools, as well as their reasons and perception behind such behavior. The motivation of this research is to identify challenges and new directions for library services for older adults.

According to the American Library Association (ALA) Glossary, information seeking behavior is "the methods by which a person practises information seeking" and information seeking is "the entire process of searching, locating, and retrieving information from any source" (Levine-Clark \& Cater, 2013, p. 135). The Japanese Glossary of Library and Information Science refers to information seeking behavior as "a specific behavior adopted by a person in seeking information including the confirmation and selection of information sources and search tools, search operations, and communications with librarians" (Glossary Editorial Committee in Japan Society of Library and Information Science, 2013, p. 109). In line with this, this research defines information seeking behavior at public libraries as "a behavior adopted when seeking library materials and information with the use of information sources and search tools of public libraries".

Ruthven (2010) presented a conceptual model of the dynamics of information seeking by public library clients in an online environment. The model provided an integrated approach to understanding the way library clients behave in selecting information appropriate to their needs. The model not only describes the flow of information seeking activities but also acknowledges the influence that clients' cognitive/affective state has in moderating this flow as well as the context and time in which this occurs. While this study covers only online libraries, our research covers real space.

While there have been previous studies on the usage patterns of older adults, including the purpose of their library use (Kawamura, Toshimori, \& Uematsu, 2010), there have been few studies dealing with the behavior of older adults at libraries. Donkai and Mizoue (2015) proposed a research method for investigating the information seeking behavior of older adults at libraries, and evaluated its effectiveness in pilot studies with library volunteers. Using the mentioned research method, the current study investigated the characteristics of information seeking behavior of older adults including those who do not frequently use libraries in their daily lives.

Robertson-Lang (2011) explored the search patterns of older adults who found highquality health information online. They also investigated the time allocated to various search states among participants who found high-versus low-quality sites. The study obtained descriptive information about the types of health topics that seniors researched, and whether they were critical consumers of information found online. Sharit, Hernández, Czaja, and Pirolli (2008) investigated the influence of knowledge (particularly Internet, Web browser, and search engine knowledge) and cognitive ability on the online information seeking of older adults. The emphasis on cognitive aspects was informed by a modelling framework of search 
engine information-seeking behavior. An objective of this study was to investigate the relationship between Internet-related knowledge and information-seeking performance, and whether this relationship differs depending on whether the search problems are simple or complex. Sharit, Hernández, Czaja, and Pirolli (2008) research focused on Web searching.

Sugie (2011) carried out a qualitative analysis of interview records to obtain explanations of the information seeking behavior of library uses, by generating concepts and categories relating to the behavior. However, this kind of research does not capture how the subjects actually seek information, and only analyzes the subjects' recall and perceptions. This method does not yield a complete picture of library users' behavior as there may be behavior that the users have forgotten or may not even be aware of. Childers (1997) did interviews with library patrons who had just finished their information seeking tasks, but also observed and note recorded their information seeking behavior. In any case, neither of these studies cover older adults.

Experiments on the information seeking behavior were conducted at a public library in this research which consists of experiments for understanding actual behavior and interviews for clarifying their perceptions including needs toward public libraries. Analyses were made with the use of interview transcripts followed by discussions conducted on the basis of such analyses and the survey results.

The experiments were carried out in Sapporo Chuo Library, a municipal central library in Sapporo city of Hokkaido, Japan. This library was established as Sapporo City Library in 1950 and renamed Sapporo Chuo Library in 1979. This facility holds 925,575 books including electronic books, and has 102,917 registered members. Its gross floor area amounts to $9,049 \mathrm{~m}^{2}$ (Sapporo Chuo Library, 2016). There are six online public access catalog (OPAC) terminals for the use of library patrons, and a Web OPAC for online access. General books and magazines are shelved on the first floor of the library and newspapers and reference books, etc. on its second floor. Both floors were used for the relevant experiments. Visitors are required to use outdoor stairways to move between floors. There are library counters on both floors.

\section{STUDY METHOD}

\section{Recruitment of Subjects}

The survey was carried out on February 27 and 28, 2016 with twelve subjects. They belonged to a non-profit organization engaging in civil activities in Sapporo City of Hokkaido. In this non-profit organization, members exchange information mainly via its contact network using email and Internet. Therefore, members are required to own a PC or equivalent to enable him or her to send and receive emails, access websites, and so on. The non-profit organization was approached for help to recruit participants for the study. The organization members who agreed to participate comprised one person in her late 50's, five in their late 60's, five in their early 70's, and one in his late 70's. Table 1 gives the profile of the participants.

\section{Structure of Each Study Session}

Each session was scheduled to take a total of 90 minutes, comprising a 20 -minute briefing about the survey, a 40-minute experiment, and a 30-minute interview. Six sessions were conducted in total with three sessions per day and two subjects per session. In the first 20 minutes, participants were briefed on the survey, shown how to operate a tablet computer and 
Table 1. Attributes of Research Subjects

\begin{tabular}{llll}
\hline No. of Subject & Age & Sex & Frequency of Visiting Public Libraries \\
\hline S1 & 71 & M & Once in a few months \\
S2 & 66 & M & Three or four times in a month \\
S3 & 69 & F & A few times in a month \\
S4 & 73 & F & Once in a month \\
S5 & 67 & M & Once or twice in a year \\
S6 & 75 & M & Almost none \\
S7 & Late 50s & F & Almost none \\
S8 & 73 & F & Almost none \\
S9 & 71 & F & Almost none \\
S10 & Late 60s & F & Almost none \\
S11 & 73 & F & Almost none \\
S12 & 67 & M & Almost none \\
\hline
\end{tabular}

Table 2. Outline of Literature search game

\begin{tabular}{llll}
\hline Question & Type of Material & Task & $\begin{array}{l}\text { Location of } \\
\text { Material }\end{array}$ \\
\hline 1 & General books & To search for a book on a designated theme & $1 \mathrm{~F}$ \\
2 & General books & To search a designated book & $1 \mathrm{~F}$ \\
3 & Newspaper articles & To search a designated newspaper article & $1 \mathrm{~F}$ \\
4 & Reference books & $\begin{array}{l}\text { To research a designated matter using } \\
\text { reference Books }\end{array}$ & $2 \mathrm{~F}$ \\
5 & Magazine articles & To search a designated magazine article & $2 \mathrm{~F}$ \\
\hline
\end{tabular}

asked to search using library resources included in the experiment (such as the OPAC). The library reference counters were not mentioned intentionally.

\section{Experiment Tasks}

A Literature Search Game was played as an experiment with the use of a tablet computer (iPad). In this game, a task was first displayed on the tablet computer. To complete the task, the subjects individually sought information using resources in the library such as library materials and tools. The researcher checked their answers on a task-by-task basis. Passwords for the subjects to advance to the next task were provided only if they had correct answers so that their skill in operating the tablet could be confirmed. This password system meant that the subjects could enjoy the tasks with an increased game element. The actions of the subjects during the experiment were directly observed and recorded by the researcher himself/herself.

As illustrated in Table 2, the literature search game had five tasks involving different kinds of information searches. For the purpose of engaging the interest of older adults, two kinds of themes titled Dementia Prevention and Preparations for end of life (Shu-Katsu) had been prepared, each assigned to a different subject of the pair in a single session. Subject 1 (S1), Subject 3 (S3), Subject 4 (S4), Subject 5 (S5), Subject 8 (S8) and Subject 10 (S10) as listed in Table 1 were assigned Dementia Prevention, and Subject 2 (S2), Subject 6 (S6), 
Subject 7 (S7), Subject 9 (S9), Subject 11 (S11) and Subject 12 (S12) were given Preparations for end of life.

\section{Interview}

A semi-structured interview method was employed for the interview with the subjects. The question items addressed the subject's prior experience in using an iPad, actions during the experiment, perceptions during and after the experiment, frequency and purpose of using public libraries, and demographic information of age, sex, and current and past occupation.

\section{RESULTS}

\section{Experiment Results}

Five questions from Question1 through Question 5 had been prepared but no subject was able to reach Question 5 in this experiment. Table 3 describes the actions that the subjects adopted for respective questions. For example, in solving Question1, S1 first used an OPAC and then visited a library counter. Lastly, he went to the bookshelves to search for the right book. S10 checked the library classification system first to solve Question 3.

\section{Question 1 (Q1)}

The task was to find books on a designated theme. The most frequently adopted action of six subjects at the beginning was to search at an OPAC terminal with keyboard search, while four subjects directly went to a bookshelf, of whom two subjects stuck to the search at the bookshelves. Two subjects first visited a counter.

\section{Question 2 (Q2)}

The task was to find a designated book, such as Dictionary of inheritance, will, funeral and grave preparation and Life style for prevention of dementia based on medical date. Eleven of the twelve subjects advanced to Q2. For this question as well, six subjects went to an OPAC terminal first, forming the majority group. Three subjects approached a library counter, and two subjects went to a bookshelf directly.

\section{Question 3 (Q3)}

The task was to find designated newspaper articles. In contrast to books, newspapers are arranged on the second floor of the library. Eight of twelve subjects were able to reach this question. As well as the preceding two questions, Q3 found a majority group consisting of four subjects who used an OPAC terminal first.

\section{Question 4 (Q4)}

Three of the twelve subjects made it to Q4. The task was to find specific information using designated reference books. The reference books were also arranged on the second floor of the library. S3 immediately visited a bookshelf, while S10 first went to the first floor counter and then headed to the second floor bookshelf. S4 made a direct visit to the first floor counter and then headed to the second floor bookshelf. 
Table 3. Behaviors of research subjects

\begin{tabular}{|c|c|c|c|c|}
\hline $\begin{array}{l}\text { No. of } \\
\text { Subjects }\end{array}$ & Q1 & Q2 & Q3 & Q4 \\
\hline S1 & $\begin{array}{l}\text { (1) OPAC } \\
\text { (2) } 1 \mathrm{~F} \text { Counter } \\
\text { (3) Bookshelves }\end{array}$ & $\begin{array}{l}\text { (1) OPAC } \\
\text { (2) Bookshelves }\end{array}$ & $\begin{array}{l}\text { (1) OPAC } \\
\text { (2) Bookshelves }\end{array}$ & \\
\hline S2 & $\begin{array}{l}\text { (1) OPAC } \\
\text { (2) Bookshelves }\end{array}$ & $\begin{array}{l}\text { (1) OPAC } \\
\text { (2) Bookshelves }\end{array}$ & $\begin{array}{l}\text { (1) OPAC } \\
\text { (2) } 1 \mathrm{~F} \text { Counter } \\
\text { (3) Bookshelves }\end{array}$ & \\
\hline S3 & (1) Bookshelves & (1) Bookshelves & (1) Bookshelves & (1) Bookshelves \\
\hline S4 & $\begin{array}{l}\text { (1) 1F Counter } \\
\text { (1) Bookshelves }\end{array}$ & $\begin{array}{l}\text { (1) } 1 \text { F Counter } \\
\text { (2) Bookshelves }\end{array}$ & $\begin{array}{l}\text { (1) } 1 \mathrm{~F} \text { Counter } \\
\text { (2) } 2 \mathrm{~F} \text { Counter }\end{array}$ & $\begin{array}{l}\text { (1) } 1 \text { F Counter } \\
\text { (2) Bookshelves }\end{array}$ \\
\hline S5 & $\begin{array}{l}\text { (1) OPAC } \\
\text { (2) Bookshelves } \\
\text { (1) Bookshelves }\end{array}$ & $\begin{array}{l}\text { (1) OPAC } \\
\text { (2) } 1 \text { F Counter } \\
\text { (3) Bookshelves } \\
\text { (4) Nearby Library } \\
\text { Staff } \\
\text { (1) Bookshelves }\end{array}$ & & \\
\hline S7 & $\begin{array}{l}\text { (1) OPAC } \\
\text { (2) Bookshelves }\end{array}$ & $\begin{array}{l}\text { (1) OPAC } \\
\text { (2) Bookshelves }\end{array}$ & $\begin{array}{l}\text { (1) OPAC } \\
\text { (2) Floor Map } \\
\text { (3) Bookshelves }\end{array}$ & \\
\hline S8 & $\begin{array}{l}\text { (1) Bookshelves } \\
\text { (2) } 1 \mathrm{~F} \text { Counter } \\
\text { (3) Bookshelves }\end{array}$ & $\begin{array}{l}\text { (1) OPAC } \\
\text { (2) Bookshelves }\end{array}$ & $\begin{array}{l}\text { (1) OPAC } \\
\text { (2) Bookshelves }\end{array}$ & \\
\hline S9 & $\begin{array}{l}\text { (1) Bookshelves } \\
\text { (2) } 1 \text { F Counter } \\
\text { (3) Bookshelves }\end{array}$ & & & \\
\hline S10 & $\begin{array}{l}\text { (1) OPAC } \\
\text { (2) Counter } \\
\text { (3) Bookshelves }\end{array}$ & $\begin{array}{l}\text { (1) } 1 \mathrm{~F} \text { Counter } \\
\text { (2) Bookshelves }\end{array}$ & $\begin{array}{l}\text { (1) Classification } \\
\text { (2) } 1 \mathrm{~F} \text { Counter } \\
\text { (3) } 2 \mathrm{~F} \text { Counter } \\
\text { (4) Bookshelves }\end{array}$ & $\begin{array}{l}\text { (1) } 1 \mathrm{~F} \mathrm{Counter} \\
\text { (2) } 2 \mathrm{~F} \text { Counter } \\
\text { (3) Bookshelves }\end{array}$ \\
\hline S11 & $\begin{array}{l}\text { (1) OPAC } \\
\text { (2) } 1 \mathrm{~F} \text { Counter } \\
\text { (3) Bookshelves }\end{array}$ & $\begin{array}{l}\text { (1) } 1 \text { F Counter } \\
\text { (2) Bookshelves }\end{array}$ & & \\
\hline $\mathrm{S} 12$ & $\begin{array}{l}\text { (1) } 1 \mathrm{~F} \text { Counter } \\
\text { (2) Bookshelves }\end{array}$ & $\begin{array}{l}\text { (1) OPAC } \\
\text { (2) } 1 \text { F Counter } \\
\text { (3) Bookshelves }\end{array}$ & $\begin{array}{l}\text { (1) } 1 \mathrm{~F} \text { Counter } \\
\text { (2) } 2 \mathrm{~F} \text { Counter }\end{array}$ & \\
\hline
\end{tabular}

\section{Overview}

Seven of the twelve subjects did not change their initial behavior all the way through the questions. On the other hand, four subjects (excluding one who could not pass Q1) adopted a different behavior for individual questions. There was a bias in the perception of the subjects with regard to search methods, represented by the fact that they did searching almost exclusively using OPAC terminals and/or by reference counter. 


\section{Feedback After Experiment}

Typical opinions were derived from feedback obtained after the experiments. Seven of the twelve subjects said that the experiments had been interesting and fun. S3 expressed her positive feeling toward the experience of operating the tablet: "Touching a tablet itself was fun. How to present questions through the tablet was also interesting." S7 gave a reason for that with regard to search methods: "The experiment was getting enjoyable after I started to understand the call number system." S11 said, "Everything was a new experience to me. I got nervous but it was fun." All of these subjects showed positive attitudes toward the library and library services.

\section{Interview of Subjects: Analyses}

Voice recordings were collected using of an IC recorder (i.e. digital voice recorder) during the interviews. Transcripts were created from the voice recordings and subsequently open coding and focused coding (i.e. the researcher re-codes guided by specific thematic issues) were carried out.

For the purpose of additionally examining user perceptions and changes in such perceptions, codes for behavior and perceptions were classified into different categories so that their relationships could be analyzed. In addition, codes for behavior and perception before, during and after the experiment were sorted into different categories. Accordingly, the following nine categories were introduced: (a) Experience at Library; (b) Experience in Information Seeking in Daily Life; (c) Information Seeking Behavior during Experiment; (d) Perception in Information Seeking Behavior in Daily Life; (e) Purpose for Using Library; (f) Perception in Information Seeking Behavior during Experiment; (g) Difficulty in Seeking Behavior during Experiment; (h) Feedback on Information Seeking Behavior during Experiment; and (i) Perception of Public Libraries after Experiment.

For instance, the code of Seeking-Oriented was allocated to the following text and then the category of $(f)$ Perception in Information Seeking Behavior during Experiment was allocated to the code of Seeking-Oriented:

- Researcher: "You have just had an experience of searching for reading materials. What were you going to do first when you read a task?"

- Subject 1: "The first thing that occurred in my mind was a PC for searching. I thought I was going to search there."

\section{Information Seeking Behavior of Older Adults at Public Libraries, and Their Perceptions During Such Behavior}

The trends in information seeking behavior can be categorized into the following three patterns:

- Case 1 where Library Usage Frequency is High;

- Case 2 where Library Usage Frequency is Low, and There is Preference for Search Method;

- Case 3 where Library Usage Frequency is Low, and There is No Preference for Search Method. 


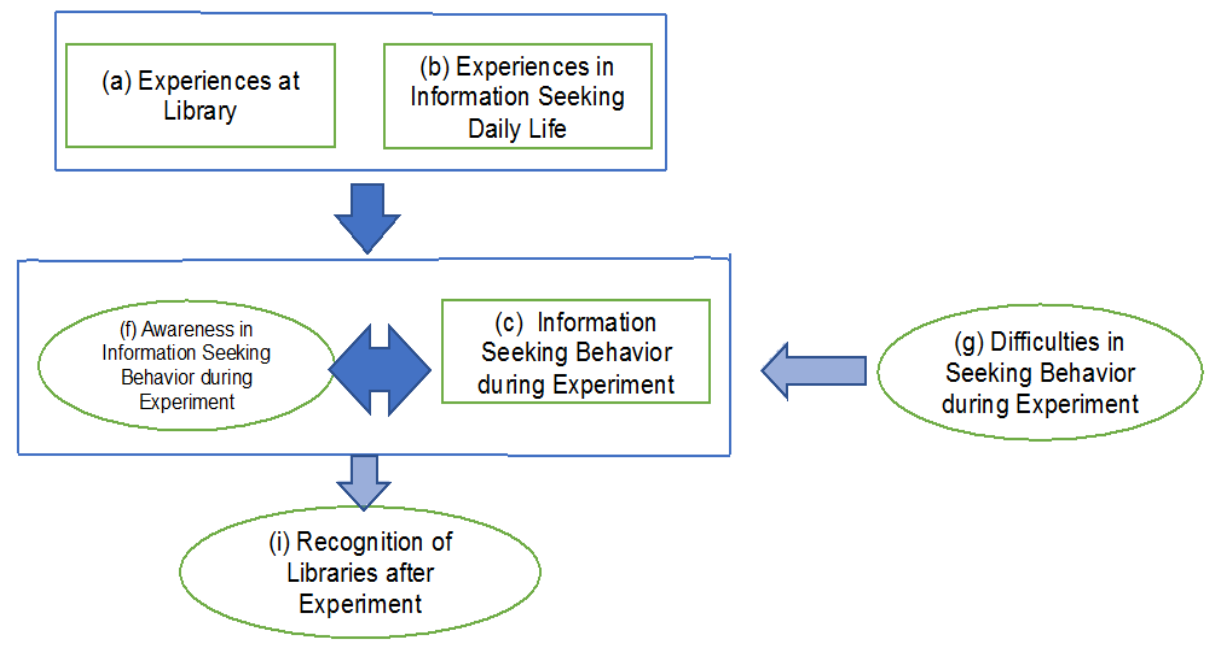

Figure 1. Case 1

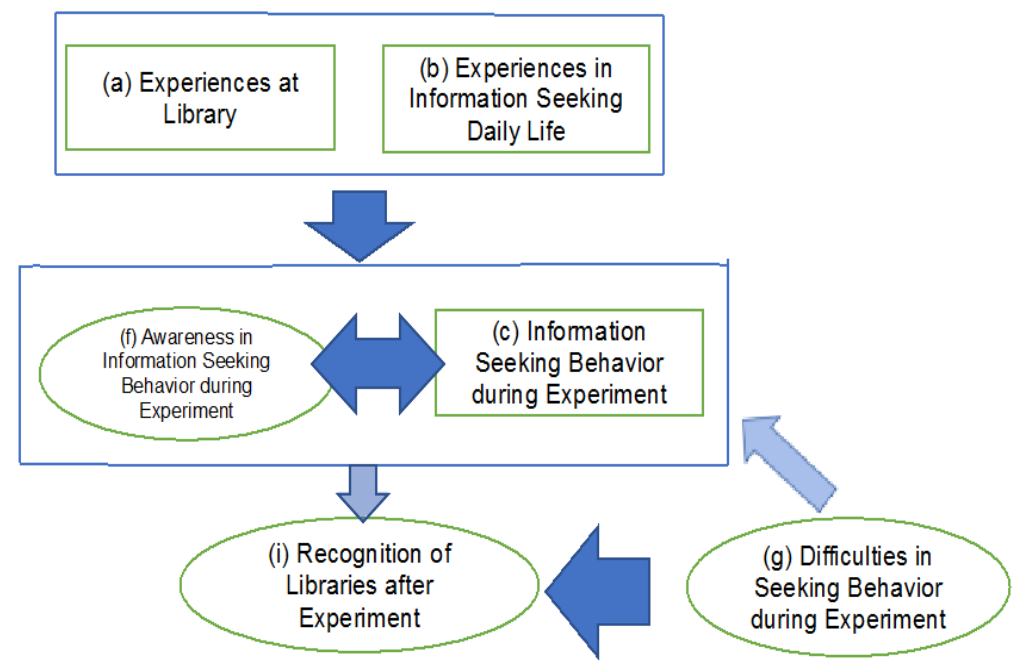

Figure 2. Case 2

\section{Case 1 Where Library Usage Frequency is High}

In cases of subjects whose library usage frequency is high (S1, S2, S3 and S4), they did not change their search methods even when they encountered a difficulty. It can be thought that (g) Difficulty in Seeking Behavior during Experiment will not make a substantial impact on (c) Information Seeking Behavior during Experiment and (f) Perception in Information Seeking Behavior during Experiment. For example, even though there was a difficulty in using a search method employed as the first option in Q1, five subjects started their search activities with the same method in Q2. Three among such subjects had frequently used public libraries. It can be concluded that older adults with high library usage frequency have knowledge and experience of information search methods at public libraries and also desire to search information in accordance with such knowledge and experiences even when they 
encounter difficulties in doing so. In fact, such older adults provided justification for their behavior during the experiment, such as "OPAC is better for search refinement." (S2), "I was trying to search with reference to shelf numbers." (S3) and "I thought that making inquiries at a counter was the quickest way to know what was arranged where." (S4).

These suggest that (f) Perception in Information Seeking Behavior during Experiment and (c) Information Seeking Behavior during Experiment are more influenced by (a) Experience at Library and (b) Experience in Information Seeking in Daily Life rather than by (g) Difficulty in Seeking Behavior during Experiment and that the relationships between $(f)$ Perception in Information Seeking Behavior during Experiment and (c) Information Seeking Behavior during Experiment are substantial.

Also, it seems that the experiment caused the subjects with high library usage frequency to renew their ideas on how to use public libraries and to regain an intention to use public libraries. It was found that (c) Information Seeking Behavior during Experiment and (d) Perception in Information Seeking Behavior in Daily Life affected (i) Perception of Public Libraries after Experiment and that their perception had been changed through the experiment. In the following figure, the darker/thicker arrows represent stronger links.

\section{Case 2 Where Library Usage Frequency is Low and There is a Preference for a Search Method}

In cases where the subjects had not frequently used public libraries and had a preference for a search method (S5 and S6), they also did not change their search strategy as was the case with the subjects with high library usage frequency. However, their perception of public libraries worsened due to the difficulties they experienced during the experiment, which means that $(g)$ Difficulty in Seeking Behavior during Experiment influenced (i) Perception of Public Libraries after Experiment.

Regarding the two subjects with low library usage frequency (S5 and S6), it was found that (a) Experience at Library and (b) Experience in Information Seeking in Daily Life had a considerable impact on $(f)$ Perception in Information Seeking Behavior during Experiment and (c) Information Seeking Behavior during Experiment and that they had a preference for a search method adopted at public libraries. For instance, S5 described his past library usage and provided the reason he had been making reservations via a Web OPAC: "It is very easy to make an online reservation. They notify me when my book becomes available. Then this book will soon be got ready for lending. I will be able to get it without any trouble." Notably, they searched mainly using an OPAC terminal in this experiment. Even though they faced a difficulty during searching, the only method they used for searching activities immediately after reading a task was an OPAC terminal. In other words, rather than $(g)$ Difficulty in Seeking Behavior during Experiment, their preference resulting from (a) Experience at Library and (b) Experience in Information Seeking in Daily Life had more impact on $(f)$ Perception in Information Seeking Behavior during Experiment and (c) Information Seeking Behavior during Experiment.

With regard to (i) Perception of public libraries after Experiment, the said subjects stated, "I was not interested or aware of anything." (S5) and "I was a little bit interested, but the feeling that the experiment was difficult outweighed it." (S6). It is deemed that "(i) Perception of Public Libraries after Experiment" was substantially influenced by " $(g)$ Difficulty in Seeking Behavior during Experiment" since (g) Difficulty in Seeking Behavior during Experiment had not been able to be settled due to the unchanged (c) Information Seeking Behavior during Experiment. 


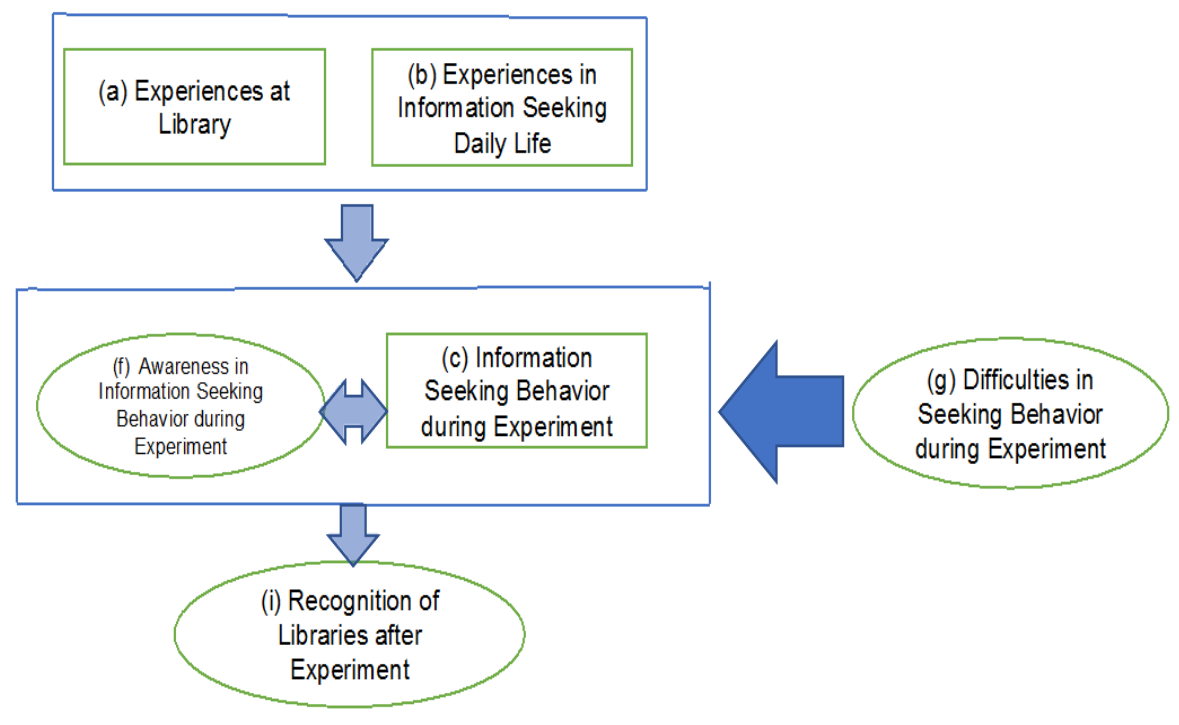

Figure 3. Case 3

Case 3 Where Library Usage Frequency is Low and There is No Preference for a Search Method

Lastly, the case where library usage frequency is low and there is no preference for a search method applied to six subjects (S7, S8, S9, S10, S11 and S12). The subjects with low library usage frequency and had no preference for a search method changed their search method from question to question.

It should be noted, however, that all the subjects with low library usage frequency and no preference for a search method became aware of the convenience of information seeking tools such as OPAC terminals and call numbers, and accordingly expressed their intentions to use such tools going forward. Therefore, as is the case with the subjects with high library usage frequency, it can be said that (c) Information Seeking Behavior during Experiment and (f) Perception in Information Seeking Behavior during Experiment affected (i) Perception of Public Libraries after Experiment.

It can be argued that library usage frequency affects information seeking behavior and perception relating to them. Further, they indicate that low perception and proficiency regarding information seeking tools influence information seeking behavior and perception relating to them irrespective of library usage frequency. Even older adults with high library usage frequency discovered new ways to use public libraries through the experiment.

\section{DISCUSSION AND CONCLUSION}

This study of the information seeking behavior of older adults at public libraries has employed a combination of experiment and interview. The information seeking behavior of older adults at public libraries can be categorized into the following three patterns: Case 1 where Library Usage Frequency is High; Case 2 where Library Usage Frequency is Low and There is a Preference for a Search Method; and Case 3 where Library Usage Frequency is Low and There is No Preference for a Search Method. 
Older adults with high library usage frequency did not change their search strategy even where they encountered a difficulty in the experiment, which means their behavior and perception during the experiment were influenced more by their prior library experience than by such difficulty. Also, the relationship between the perception and behavior during the experiment were substantial.

With regard to older adults with low library usage frequency and a preference for a search method, as in the case of older adults with high library usage frequency, their prior experience had a substantial impact on their behavior and perception during the experiment and they stuck to their search strategy even though they faced a difficulty during the experiment. In contrast, for older adults with low library usage frequency and no preference for a search method, experiencing a difficulty during the experiment affected their perception of public libraries after the experiment, but didn't influence their behavior and perception during the experiment.

Older adults with low library usage frequency and no preference for a search method did change their search method from question to question. This suggests that the difficulty they experienced during the experiment had an impact on their behavior and perception during the experiment. In common with the case with older adults with high library usage frequency, they became aware of the convenience of information search tools, etc.

Even some older adults with personal computer (PC) experience have some difficulties to look for appropriate information at public libraries. So these results suggest that older adults need to know a search tool at public libraries that is appropriate for them. A challenge for public library services lies in the low perception of information search tools and proficiency in using them. Implementing an orientation program using the literature search game as designed in this study is a promising option for raising proficiency in using information search tools. Such literature search games, appropriately customized for the library and its patrons, will help to publicize information search tools at public libraries as well as support group activities and lifelong learning.

A limitation of this research is that it was not able to cover older adults who had not used a PC. In addition, comparisons with other age groups were not made in this research. Specifically, this research has examined the low perception of and proficiency in using call numbers. It raises the question of whether library users who have received library use instruction at school have better proficiency in using public libraries. As future work, we intend to study public library users of different age groups, who have received library use instruction at school.

\section{REFERENCES}

Childers, T. A. (1997). Using public library reference collections and staff. Library Quarterly, 67(2), 155-173.

Cabinet Office, Government of Japan. (2016). Annual report on the aging society, 2016 [In Japanese]. Tokyo: Insatsu-tsuhan. Retrieved from http://www8.cao.go.jp/kourei/whitepaper/w-2016/html/zenbun/index.html

Cabinet Office, Government of Japan. (2018). Annual report on the aging society, 2018 [In Japanese]. Tokyo: Insatsu-tsuhan. Retrieved from https://www8.cao.go.jp/kourei/whitepaper/w-2018/zenbun/30pdf_index.html

Donkai, S., \& Mizoue, C. (2015). Visualizing information seeking behaviors of older adults at public libraries: Reflective learning and information literacy. In Proceedings of the 6th International Conference on Asia-Pacific Library and Information Education and 
Practice (A-LIEP 2015), 28-30 Oct 2015, Manila, Philippines (pp. 342-350). Manila: University of the Philippines, School of Library and Information Studies.

Glossary Editorial Committee in Japan Society of Library and Information Science. (2013). Glossary of library and information science (4th ed.) [In Japanese]. Tokyo: Maruzen.

Hayashi, K. (2015). Basic research on media environment of older people [in Japanese]. Bulletin of Edgawa University, 25, 229-236.

Kawamura, Y, Toshimori, A., \& Uematsu, S. (2010). The library utilization behaviour of residents at the household level in the districts with good access to libraries in a widespread area: On the basis of a resident survey in Sapporo City [in Japanese]. Journal of Japan Society of Library and Information Science, 56(2), 65-82.

Levine-Clark, M., \& Carter, T. M. (Eds.). (2013). ALA glossary of library and information science (4th ed.). Chicago: American Library Association.

Ministry of Internal Affairs and Communications, Japan. (2012). 2012 White paper information and communications in Japan. Retrieved from http://www.soumu.go.jp/johotsusintokei/whitepaper/h24.html

Robertson-Lang, L., Major, S., \& Hemming, H. (2011). An exploration of search patterns and credibility issues among older adults seeking online health information. Canadian Journal on Aging, 30(4), 631-45.

Ruthven, J. (2010). The information-seeking behavior of online public library clients: a conceptual model. The Australian Library Journal, 59(1-2), 30-45.

Sapporo Chuo Library. (2016). Library in Sapporo City [In Japanese]. Retrieved from http://www.city.sapporo.jp/toshokan/guide/sisin/liv/2016.html

Sharit, J., Hernández, M. A., Czaja S.J., \& Pirolli P. (2018). Investigating the roles of knowledge and cognitive abilities in older adult information seeking on the Web. ACM Transactions on Computer-Human Interaction, 15(1), no. 3. doi: $10.1145 / 1352782.1352785$

Statistics Bureau, Japan. (2016). Older adults from the statistics data (Topics of statistics 97) [In Japanese]. Retrieved from http://www.stat.go.jp/data/topics/topi970.htm

Sugie, N. (2011). Information-seeking behavior of public library users: Generating concepts and a theory based on a qualitative analysis of interview data [In Japanese]. Journal of Japan Society of Library and Information Science, 57(1), 1-18. 